\title{
EVALUATION OF MOBILE DEVICE INDOOR MAPS FOR ORIENTATION TASKS
}

\author{
Avaliação de Mapas Indoor em Dispositivos Móveis \\ para Tarefas de orientação \\ Rhaíssa Viana Sarot ${ }^{1}$ - ORCID: 0000-0002-2374-2475 \\ Luciene Stamato Delazari ${ }^{1}$ - ORCID: 0000-0003-0018-085X \\ ${ }^{1}$ Universidade Federal do Paraná, Departamento de Geomática, Curitiba, Paraná, Brasil. \\ E-mail: rhaissa89@gmail.com; luciene@ufpr.br
}

Received in July $03^{\text {rd }} 2018$

Accepted in August $17^{\text {th }} 2018$

\begin{abstract}
:
This research investigates subjective user preference for using Floor Plans and Schematic Maps in an indoor environment, and how users locate and orient themselves when using these representations. We sought to verify the efficiency of these two kinds of digital maps and evaluate which elements found in physical environments and which elements found in the representations influence the user spatial orientation process. Users answered questions and performed orientation tasks which indicated their level of familiarity with the area being studied, their understanding of the symbology used, and their identification of Points of Interest (POI) in the environment. The initial results indicated a preference for the Schematic Map, because users thought that the symbology used on the map adopted was easy to understand.
\end{abstract}

Keywords: Indoor mapping; Mobile devices; Spatial orientation.

\section{Resumo:}

A pesquisa investiga a preferência subjetiva do usuário no uso dos mapas Planta Baixa e Mapa Esquemático em um ambiente interno, e a forma como o usuário se localiza e se orienta ao se utilizar destas representações. Buscou-se verificar a eficiência destes dois mapas disponibilizados em meio digital e avaliar quais elementos encontrados no ambiente físico e na representação influenciam o processo de orientação espacial. Os usuários responderam perguntas e realizaram tarefas de orientação que relacionam seu nível de familiaridade com a área de estudo, a compreensão da simbologia proposta, e a identificação de Pontos de Interesse (POI) no ambiente. Os resultados iniciais indicam uma preferência pelo Mapa Esquemático, devido aos usuários acharem a simbologia adotada no mapa de fácil compreensão.

Palavras-chave: Mapeamento indoor; Dispositivos móveis; Orientação espacial.

How to cite this article: SAROT, R. V. and DELAZARI, L. S. Evaluation of Mobile Device Indoor Maps for Orientation Tasks. Bulletin of Geodetic Sciences, Vol. 24 (4): 564-584, Oct-Dec, 2018. 


\section{Introduction}

The structural complexity of buildings, the large amount of information that can be found in an indoor environment distributed on different storeys of the structure, and the development of technologies for indoor positioning have provided input for the development of indoor cartography (Nossum, 2013). The new applications that arose during the process of integration between sets of information and positioning services provided through mobile devices by mobile network companies have made mapping product users more demanding. This has stimulated demand for new tools and the creation of indoor maps that can supply this market. Research into solutions and comprehension of the problems related to indoor navigation system utilization have become essential to the development of indoor mapping (Schiller \& Voisard, 2004; Zlatanova et al, 2013).

Indoor mapping research focuses more on internal positioning systems and less on representations of such environments. However, there is a need for such information to be represented, in order to assist the process of user orientation and navigation in the environment. Indoor cartography should take into consideration the user's orientation and overview requirements, as well as issues relating to indoor navigation systems. Some representations found in the literature and which fit in with the restrictions imposed by this type of environment include Architectural Plans, Floor Plans, Schematic Maps and "You-Are-Here" maps (YAH) (Nossum,2013).

In the case of Floor Plans, the information detail level is reduced, and the choice of symbols and colors is aimed at general users. Objects such as windows and doors are not represented. In this category we can cite maps of shopping malls, airports and subways, among other environments that have a high flow of people (Nossum, 2013).

On Schematic Maps the connections between objects have more relevance than the objects' geographic position, size and shape (Forrest, 2015). The purpose is to link information to a route in a quick and efficient way. Information is presented through linear features that maintain the topological relation between the object in the physical environment and the represented object. In general, they are used to represent transportation system routes (such as highways and subways) (Avelar \& Hurni, 2006; Nossum, 2011).

In addition to the different representations influencing the cartographic communication process, the user's location at the site and the restrictions and physical characteristics of the indoor environment also affect how the user reads and understands the map (Dogu \& Erkip, 2000; Montello, 2010; Sarot, 2015). Montello (2010) describes problems such as lack of user orientation caused by YAH maps that are not aligned with the environment, i.e., the user's current position differs from the direction in which the map is pointing at the current moment (rotation varying from $0^{\circ}$ to $360^{\circ}$ ). As a consequence, users of non-aligned maps establish mental routes that do not reflect reality, and increase the time spent on studying the map and determining routes.

The issue of static maps not being aligned with the environment can be minimized with the use of maps visualized through mobile devices. These enable the user to interact with the system via interface, as well as providing options for rotation, zoom and searching on the system. These advantages, along with the diversity of information that can be represented on different scales on the screen, increase user preference for navigation with mobile devices (Lehtinen et al, 2012). 
The choice of this kind of representation generates other questions (Lehtinen et al, 2012). Antunes et al. (2017) provide a review of characteristics that should be considered regarding mapping system usability, such as mobile device display resolution and screen size; system interface design (map area size, tool size), and user preference.

Although there are different ways to present this information (paper vs. digital), and different forms of representation (Floor Plan vs. Schematic Map), it is still not possible to affirm which is the best way to present the indoor environment to the user so as assist to their spatial orientation and navigation (Schmidt (2012 apud Darken et al, 2002; Vinson, 1999); Sarot, 2015). Some studies show that maps being available on mobile devices provides users with the ability to interact with the representation while moving around the building (Sarot, 2015; Antunes, 2016).

As such, this research is based on the hypothesis that user spatial orientation in an indoor environment suffers changes related to the kind of presentation and representation used. We seek to evaluate which elements found in the physical environment and in the representation can influence the user wayfinding and orientation process. We therefore propose to perform this evaluation with the aid of a mobile device and two kinds of indoor representation, namely a digital Floor Plan and a digital Schematic Map. Representation efficiency is evaluated through an online questionnaire and also through wayfinding and orientation tasks that verify the user's level of familiarity with the indoor environment; their understanding of the symbols used on the maps; the identification of possible spatial reference points; and subjective user preference for the maps evaluated.

The users taking part in the tests were divided in two groups: Group I evaluated the Floor Plan; Group II evaluated the Schematic Plan. Both groups had users who were used to walking inside the building, as well as users who were not familiar with the environment.

This article is structured as follows: firstly we establish the parameters that should be considered in indoor cartography to help to determine user positioning and the necessary characteristics of the two representations evaluated. The second stage relates to the methodology used for map generation and the main issues addressed by the evaluation questionnaire. The third stage describes the tasks performed by the users and the results obtained. Finally, we address some conclusions and recommendations for future research.

\section{Related Work}

The indoor environment is defined by spaces that go to form one or more buildings, comprising their architectural components (roof, walls); their spatial components (entrances, corridors, rooms) and objects (doors, stairs); as well as components considered irrelevant for user orientation and navigation of the users in the environment (furniture) (OGC, 2014). The OGC IndoorGML standard (OGC, 2014) establishes parameters for defining static and moving features that assist user positioning in the indoor environment, based on the representation of the spatial properties and the resources existing at the site.

Spatial information in these environments can be categorized according to its use in space management and, in this case, it places emphasis on the building, maintenance and security of the environment (internal construction and facilities) (OGC, 2014). Moreover, it can also classify the use of spaces according to the needs of their users (OGC, 2014; Delazari et al, 2014; Sarot, 2015). 
The model considers that the interior space $(S)$ is formed by a set of $n$ cells $(c)$, where $S=\{c 1, c 2, \ldots, c n\}$, i.e., the building (S) is comprised of a set of rooms (c). Each cell contains an identifier (ID) and can border (common neighborhoods) with other cells, although the cells cannot overlap. The cells may contain geometric information (two-dimensional, three-dimensional), topological information (adjacencies and connectivity) and semantic information (classification, type) (OGC,2014).

The diversity of cellular spaces within the indoor environment enables multi-layered representation of the environment. Breaking down the layers forms sublayers in the cellular space, i.e., a single indoor environment can be interpreted semantically through different cellular spaces. Through this method is possible to represent the hierarchical structure of the indoor environment (OGC, 2014).

Nossum (2013) establishes the purpose of using maps based on user tasks or needs and thus defines the hierarchy of the information that is considered essential in map production. Three solutions stand out: Architectural Plans, Floor Plans and Augmented Reality Systems. In general, maps that represent a high level of detail and information about the building structure are classified as Architectural Plans (used in local emergency scenarios); Floor Plans, the level of detail information is reduced, and the symbols and the colors target a general user, who needs to know about the environment (maps of shopping malls, airports and subways); threedimensional models, first-person Virtual Reality, Augmented Reality and Photo Reality belong to the same category. The distinction between them is found in the level of user immersion in the represented environment (used in prototypes and research projects) (Nossum, 2013).

Schematic Maps are part of the Floor Plan category, despite their level of generalization being greater than in conventional Floor Plans (Anand et al, 2000). The Intergovernmental Information Systems Advisory Council defines the schematic map as a simplified map concerned with topological precision. The connections existing between objects are more important than the geographic position, size and shape of objects (Forrest, 2015). The objective of this type of map is to link information to a route in a fast and efficient way. The problem in relation to the generation of this model is the establishment of clear relations between information about the environment and the abstract structures represented through linear features and points of interest (Nossum, 2011).

Owing to the extent to which information is generalized, Schematic Maps are represented by linear features that preserve the topological relation between the object in the environment and the representation, being useful for spatial problem-solving tasks. In general, they are used in the representation of transport system routes (highway systems and subways) and in the case of gas, water and electricity schemas (Avelar \& Hurni, 2006; Nossum, 2011).

In Forrest's (2015) study on the IndoorTubeMap, he mentions that the use of elements from the outdoor environment on indoor maps can modify user spatial orientation in some cases. In general, the only topographic information included in transport Schematic Maps are the main hydrographic elements of the region (a river, or a sea coast), since for the user, the division between earth and water is so strong that it provides a positional context of their current location on the transport network. Adding this information provides the user with an idea of scale and the extent of map coverage. In the opinion of most users, this information is more relevant than adding a statement or a scale bar on the map (Forrest, 2015).

The question of the influence that schematic map design and scale and positioning distortion has on the user is dealt with in Guo's research (2011) into the problem of planning routes. Guo's research compares a Schematic Map and a conventional map representing the London underground system. Map design was found to influence 
user preference of choice of routes, as they tend to prefer routes represented by straight lines, even if the time spent travelling increases because the distance between the beginning and end of the route is longer. Users still tend to choose routes that minimize uncertainties so as to decrease the possibility of making mistakes when determining their route mentally. As such they avoid using routes involving changing stations (Guo, 2011; Forrest, 2015).

Delazari et al. (2014) investigate the use of a Schematic Map in an indoor environment that differs from the context of using transport systems. Their research analyzes the subjective preference of the user for the Schematic Map rather than the Floor Plan in a building used for educational purposes. Despite not reaching a conclusion in relation to preference for a type of map, their research indicates that users found the symbology used on the Schematic Map easier to understand. Their research also presents possible Points of Interest (POI) and non-spatial attributes necessary for the process of user spatial orientation in the environment assessed (Delazari et al, 2014).

Considering that the user obtains orientation by means of reference points that provide new information about the environment, the spatial orientation process relates the user's level of knowledge to the environment, as well as the way that the user understands the representation, i.e., the user finds their position based on elements found at the site and looks for those elements on the representation (Schmidt, 2012). Therefore, the symbology used on the representation should make explicit the patterns and relationships of the spatial data, in such a way that the user understands the relationships of the phenomenon and their spatial distribution. The aspects relating to how the user perceives the symbology and organizes it internally should be considered (Schmidt, 2012). As such, when applying new types of representation, the user's characteristics and the circumstances in which visualizations are used should be taken into consideration (Schmidt (2012 apud Haeberling, 1999); Sarot, 2015).

\section{Methodology}

\subsection{Initial Considerations}

The first step of this research was to understand how to design a Schematic Map for an indoor environment and determine which elements (spatial and non-spatial attributes) are needed in the representation of the indoor environment in order to assist the process of user orientation and localization. Once the maps had been designed, we conducted a study to compare the subjective preferences of users with regard to Floor Plans and Schematic Maps.

The area studied consists of Blocks II and III of the Centro Politécnico located at Campus III of the Federal University of Paraná, in Curitiba-PR, Brazil. There is a large amount of information associated with these buildings, such as: classrooms, teaching laboratories, communal socialization areas, commercial establishments, department/sector rooms, employees' rooms and bathrooms. The structural complexity of the two-storey building makes user orientation within it difficult (Figure 1). 


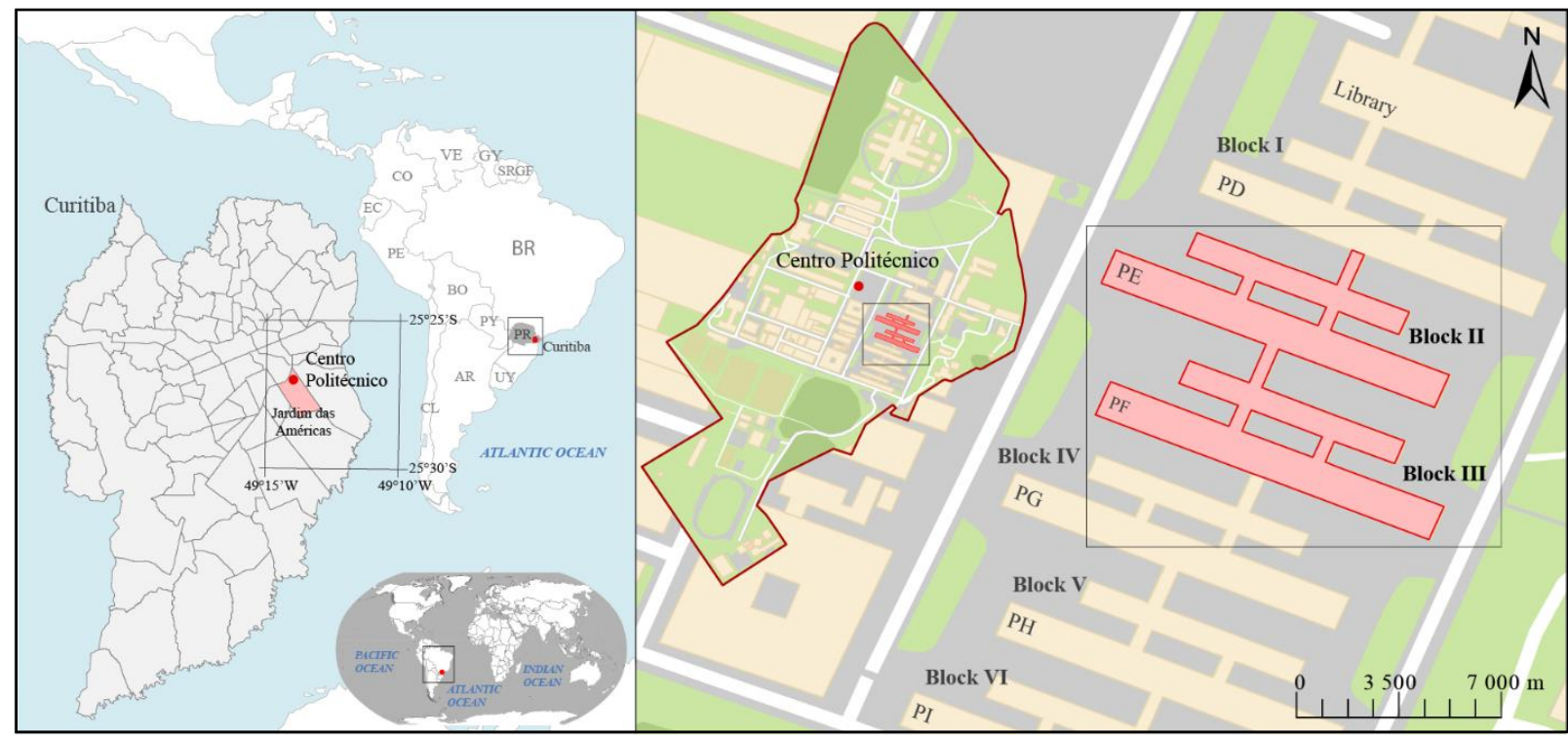

Figure 1: Map design.

The architectural plans of the two floors of this building were updated by means of topographic and cadastral data collection, in order to include on the plans man-made alterations to the structure over time. In addition to the physical characteristics of the structure, data collection of details of the area studied also took into consideration information relevant for users in the environment, such as the name of the area being studied, the name of the Block and the floor on which the objects were located.

During data collection Points of Interest (POI) were defined. They were represented according to the Floor Plan and Schematic Map specifications. Table 1 shows the difference between the graphic primitives used in each map to represent the same feature.

Table 1: POI defined for representation

\begin{tabular}{c|l|c|c}
\hline Elements & \multicolumn{1}{|c|}{ Attributes } & \multicolumn{2}{c}{ Graphic primitive } \\
\hline & \multicolumn{1}{|c}{} & Floor plans & Schematic Map \\
\hline Rooms & $\begin{array}{l}\text { Classroom/ Laboratories/ Offices/ Services stores/ } \\
\text { Others }\end{array}$ & Area & Point \\
\hline Corridors & Free access/ Restricted access & Line & Line \\
\hline Bathroom & Ladies room/ Men room/ Disabled bathroom & Area & Point \\
\hline Stairs & & Point & Point \\
\hline Way out & & Point & Point \\
\hline Lift & & Point & Point \\
\hline
\end{tabular}

The attributes of the features include their nomenclature and main characteristics. The rooms contain information related to their intended use (e.g. classrooms, offices and laboratories); the corridors show accessibility information (free or restricted access); the bathrooms are classified according to gender (female or male) or users with special needs. The symbology adopted in the representation of the possible POI is equivalent on the maps. 
Once the architectural plan had been updated, its features were generalized, based on the characteristics put forward by Nossum (2013) and Delazari et al. (2014) with regard to the Floor Plan and Schematic Map. Map generation takes into consideration the general user's need to get to know the environment and identify specific points for orientation and navigation. In research, maps should provide answers to the following spatial analyses: recognition of objects (what is it?), identification of objects (what can be found in a certain area?), navigation between points, and identification of proximity or connectivity between objects (Delazari et al, 2014).

The spatial phenomenon to be represented considers the specifications regarding the use of spaces that comprise the indoor environment, this being the information needed for the process of user orientation process in relation to the type of use the room. In this case, only the rooms and corridors that define the structure of the building remain in the representation. Objects such as windows, doors and electrical installations were removed from the plan to avoid excess information from hindering the cartographic information process between the user and the representation (Delazari et al, 2014; Sarot, 2015).

The Types of Indoor Space Use classify the rooms in relation to their intended purpose. Places that provide general services to the user, such as the Student Academic Center, secretaries' offices and janitor's storeroom were grouped together in a single category (Other). The color shades used in the representation take into consideration that from the user's point of view the information represented should not indicate different levels of importance. Therefore, the colors used do not contrast with each other and have similar saturation levels. Pictorial symbology is used for Points of Interest (POI) (bathrooms, exits, elevators, stairs and stores) (Figure 2).

\begin{tabular}{|lll|}
\hline Floor plan (symbology) & Schematic map (symbology) & Symbology adopted in both maps \\
\hline Classroom & $\mathrm{O}_{\text {Classroom }}$ & $\mathrm{O}_{\text {Laboratories }}$ \\
\hline Laboratories & $\mathrm{O}_{\text {Offices }}$ & Others \\
Ooffices & &
\end{tabular}

Figure 2: Proposed symbology.

The corridors of the buildings are represented by lines that show where user access either is or is not restricted. If access is restricted by objects in the physical environment, this is represented by red lines, so the user can instinctively feel that access is restricted.

Figure 3 shows the maps generated in this study using ArcGis 10 software. The maps were converted into .kml format in order to be made available online to users through the Google My Maps application for Android and IOS. This application enables the creation and editing of personalized maps. 


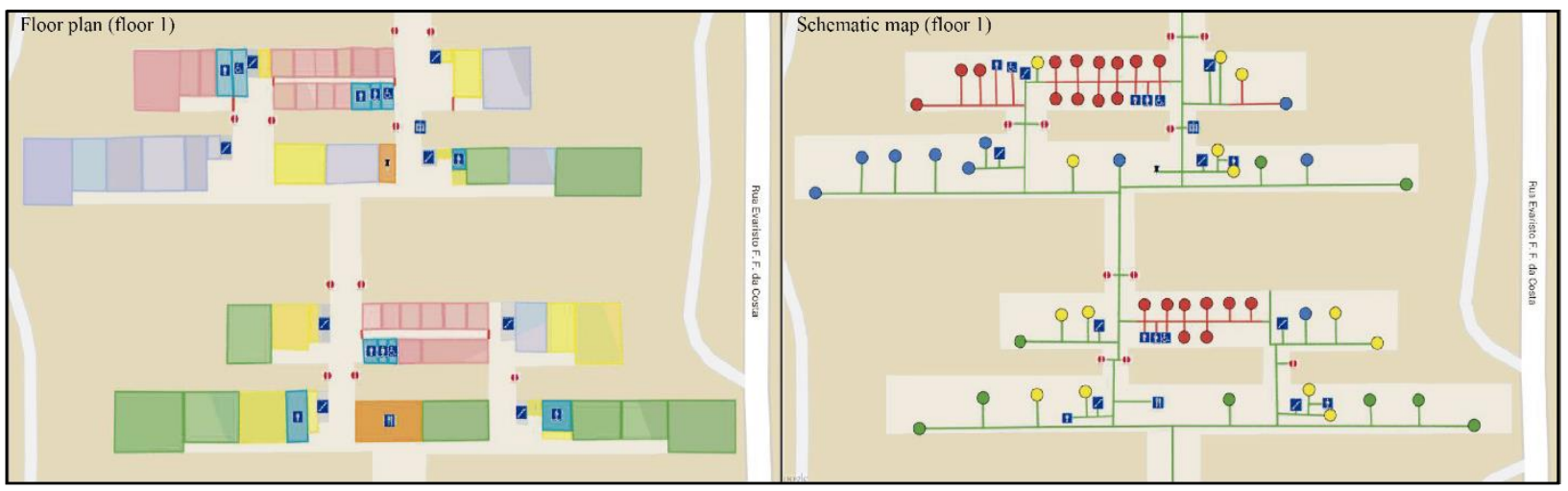

Figure 3: Maps Designed for the Area Studied (available in the MyMaps application).

In this research the mobile device used in the tests with users is a Samsung Galaxy Tab 4 Android 4.4 tablet with a 16GB memory card, Wi-fi and 3G connection, 10.1" screen and Qualcomm Quad-core Processor (1.2 GHz). However, given the variation in the size of mobile device screens found on the market, we opted to calculate the dimensions of the symbology used on the maps taking a 3.5" monitor as the average size. The symbology dimension calculation therefore takes into account the largest and the smallest features to be represented on a minimum screen measuring $50 \times 75 \mathrm{~mm}$. In this case, the distance between the building's corridors varies between 3 meters (minimum distance) and 85 meters (maximum distance).

The symbols are $2.0 \mathrm{~mm}$ in diameter and the lines are $0.5 \mathrm{~mm}$ thick, and both are within the visual accuracy range of $0.02 \mathrm{~mm}$. Another criterion taken into account was the problem of feature overlapping on the maximum visualization scale of 1:500 provided by the application, so that overlapping symbols on the representation are repositioned to facilitate the process of object identification by the user.

The MyMaps application tools enable different map scales to be seen (zoom), GPS activation to estimate local position, the possibility of map rotation in keeping with the user's current position in the environment, the exhibition of feature attributes, and the option to exhibit only features identified in specific environments of the building (objects on a given floor of the building) (Figure 4).

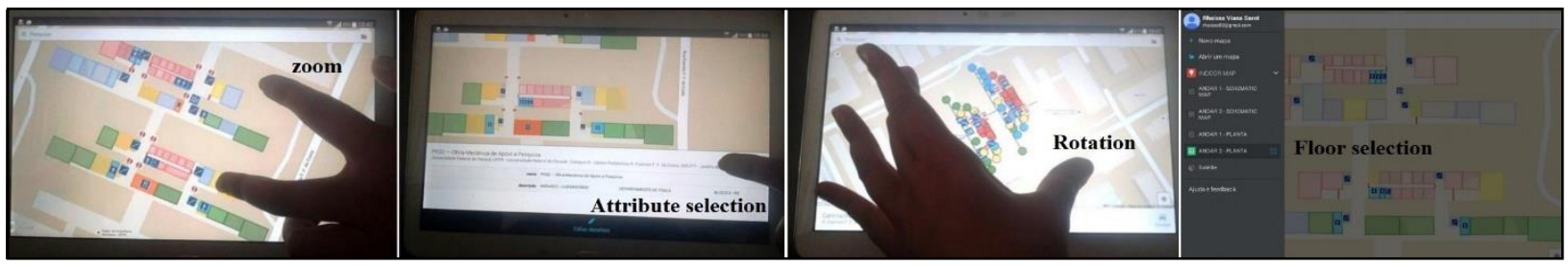

Figure 4: MyMaps application tools.

The user can also choose the cartographic base of the map from two options provided by Google, either the standard base map of the region or the satellite images of area (Figure 5). 


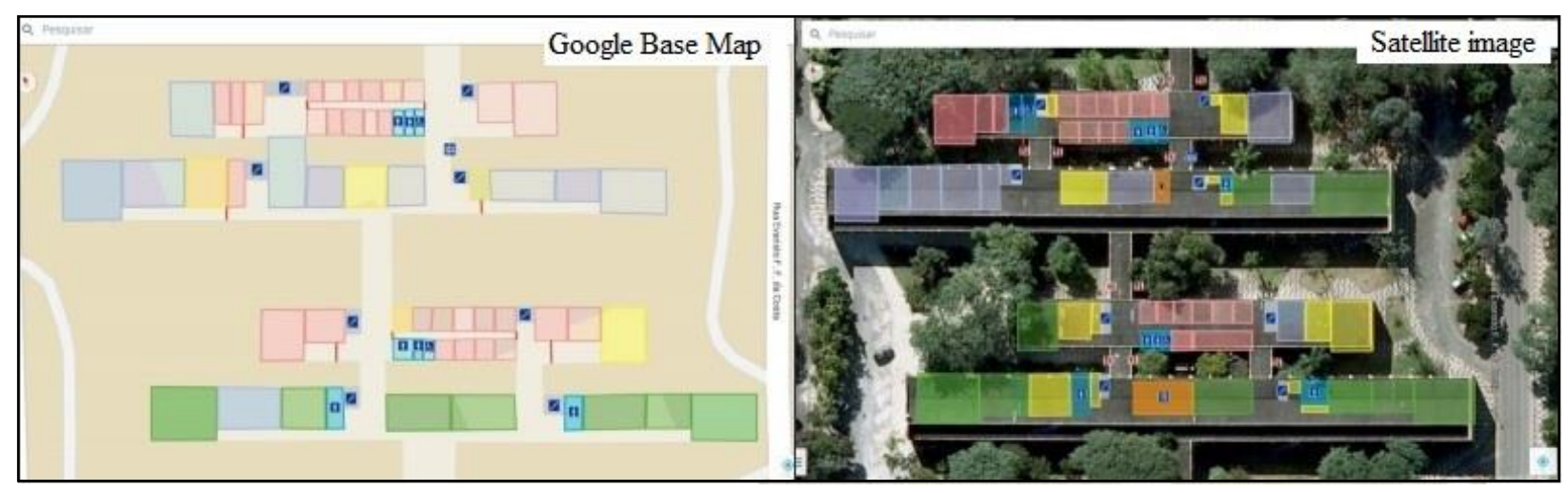

Figure 5: Base Map of the MyMaps application.

\subsection{User test}

In order to verify the advantages and disadvantages of using the indoor maps proposed in this study, an online questionnaire was prepared regarding user orientation inside the indoor environment studied here. The questions were based on the studies of Dogu \& Erkip (2000) and Schmidt (2012) and related to user identification and characterization; user familiarity levels with mobile devices and maps in general; determination of user experience with indoor maps use; determination of mental routes; user levels of familiarity with the symbology; level of user familiarity with the indoor environment, and searches for specific places on the maps.

Tests were performed using a tablet, on which users were able to see and interact with the maps. The device (Tablet) had more than one mobile Internet connection option (Wi-fi+3G) in order to minimize wireless network connection problems. The tests were performed individually to minimize possible distractions or interferences with the final result by other users (Sarot, 2015; Antunes et al, 2017).

With the aim of users becoming familiar with the software interface and becoming acquainted with the symbology of the represented elements, the researcher let users explore the map's interactivity tools. The test started after the users' agreement once they felt ready to do it. The time taken to do the test was counted with effect from user agreement (Sarot, 2015).

The test was comprised of five stages. The questions were multiple-choice with an "open field" option for users to provide additional considerations. Some elements were assessed by scores, varying from zero (little or difficult) to ten (very or easy). The assessment took into consideration the accomplishment of the tasks, the efficiency of the map based on time spent on executing the tasks, the acceptability of map and the level of difficulty faced by users in accomplishing the tasks.

During the tests user audio recordings were made to allow verification of the veracity of the observations noted by the interviewer about difficulties described by users as they performed the task (think-aloud). This method allows problems found to be assessed and time spent performing the tasks to be measured. Based on the answers obtained, some user strategies for POI identification in the indoor environment were revealed.

Analysis of the results also took into consideration user knowledge in relation to the area being studied. This allows evaluation of the maps in extreme cases of users with or without previous information about the building. 
The research analyzed 30 (thirty) people who were divided in two groups: 15 (fifteen) users evaluated the Floor Plan map (Group I) and the other half evaluated the Schematic Map (Group II). Both groups had 11 (eleven) users who knew the buildings, and 4 (four) users who were not familiar with the buildings. All stages of the research described above are shown in Figure 6.

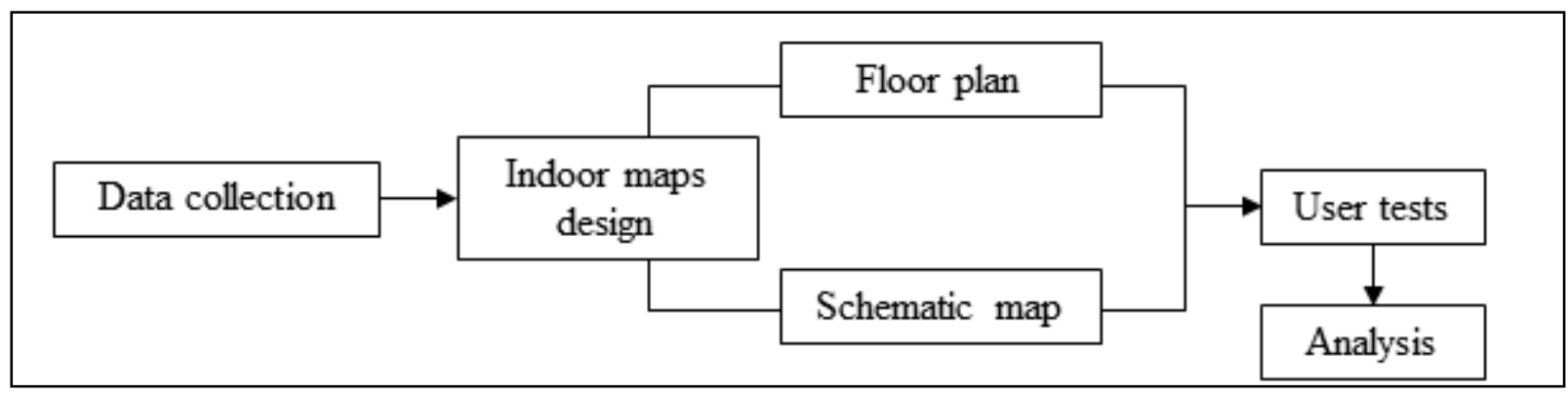

Figure 6: Research stages.

\section{Results}

The analyses were done by comparing the questionnaire results of Group I and Group II users. This took into consideration the internal subdivision of each group in relation to the each person's level of familiarity with the environment, i.e., "Experienced user" and "User with no experience". The five stages of the questionnaire along with the results obtained are described below. Some of the comments made by users when performing the test are used to explain the results. The comments were summarized for each question.

Stage 1 involved user identification and characterization. All the users of the sample had basic knowledge of text and symbology reading and interpretation. Figure 7 shows users' level of schooling (Stage 1).

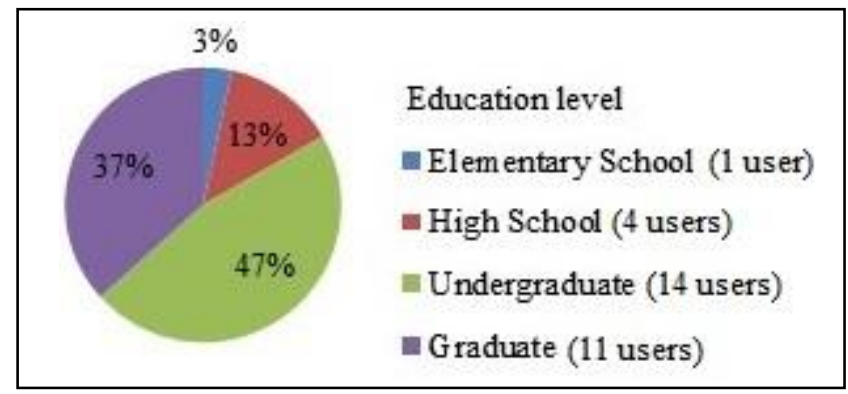

Figure 7: Participant education level (Stage 1).

Stage 2 established the level of user familiarity with mobile devices and maps in general. Figure 8 presents the questionnaire questions and the answers obtained. Table 1 provides considerations regarding the questions and comments made by users (Stage 2). 


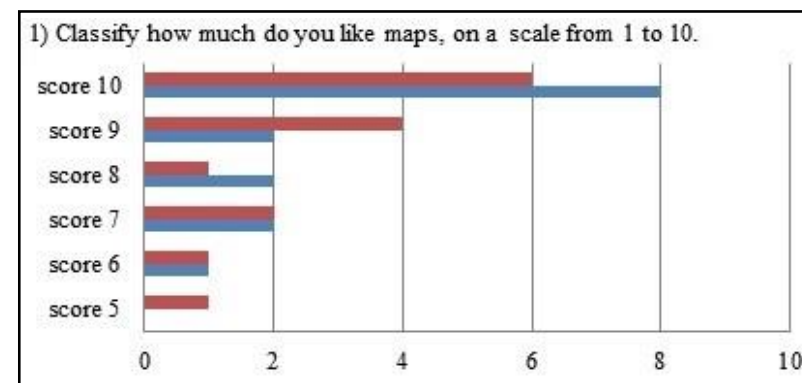

3) Do youknow how to accomplish geographic tasks using maps?

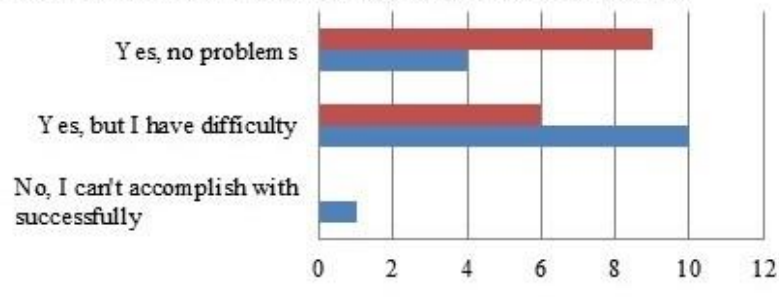

5) Have you ever used a computer program with zoom and pan tools or a computer aided design software?

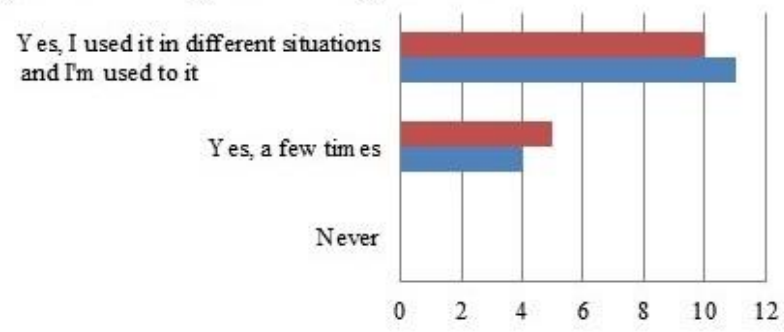

7) Classify your familiarity with mobile devices, on a scale from 1 to 10 .

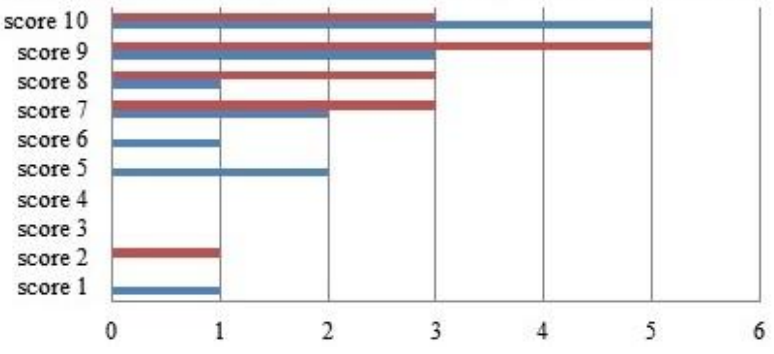

2) In your daily job, how often do you use maps (digital or paper)?

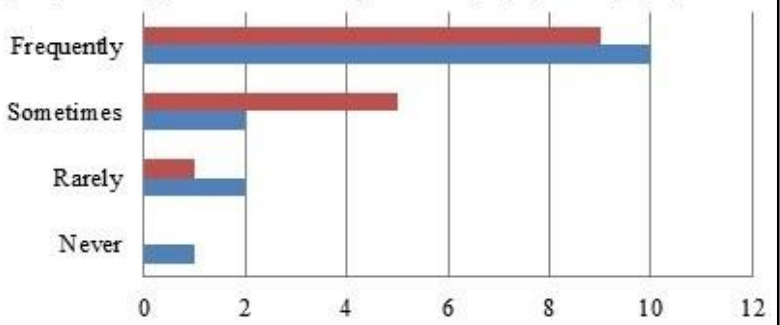

4) If you use maps, what is your preference, paper maps or digital maps?

I don't have preference, it depends on the situation

I'd rather use digital maps

I'd rather use paper m aps

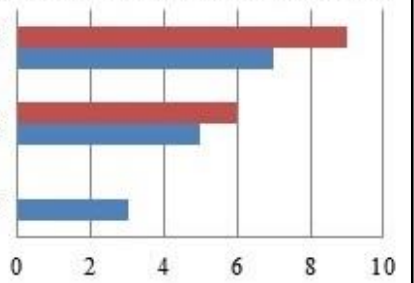

6) With what frequency do you use a mobile device?

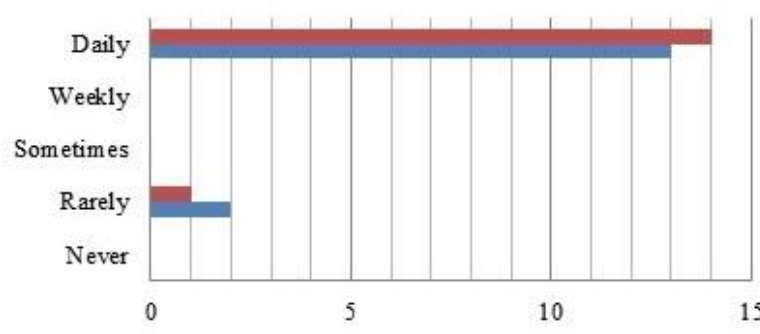

Figure 8: Use of general maps (Stage 2).

Table 1: Use of general maps (Stage 2)

\section{Stage 2 Results}

Q1: Scores below 5 indicate signs of aversion or apprehension in the use of maps. Some factors responsible for this are difficulty in reading maps, lack of experience of using maps, and difficulty in paying attention and concentrating on accomplishing tasks with maps.

Q2: A Group I user mentioned that he did not have the habit of using maps due to the lack of the need to use maps in his work.

Q3: The users mentioned that despite having difficulties in some cases, they did not consider them to be an impediment to performing the geographic tasks.

Q4: Users opting for "paper maps" were motivated by the tactile impression sensation which, according to them, makes it easy to handle maps. Users opting for "digital maps" mentioned having the habit of searching for 
Table 1: Cont.

addresses on the Internet, and problems with using digital maps (Internet signal loss and device batteries running low).

Q5: Users answering "Yes, a few times" mentioned that despite lack of contact with the tools, they understood their functionalities. Having a basic notion of tool functioning facilitates user interaction with the map, because they have already gone through the stage of learning functions and how to use tools.

Q6: Users answering "rarely" used mobile devices just for calls and SMS messages. Lack of habit of using devices can hinder access to information on the map and alter the user's behavior (feelings of frustration and irritability).

Q7: Users with scores below 5 showed difficulties in handling devices because of their age and lack of practice. They also mentioned feeling uncomfortable feeling when being forced to use them.

All the sample of users mentioned having familiarity with products provided by Google (Google Maps and Google Earth), i.e. they had minimum knowledge of the system. As the maps evaluated use the cartographic base provided by Google, it is hoped that users do not feel confused or disoriented when applying the base map. It is expected that the shape of the building contour provides the notion of scale and area covered by the map, this being the same principle found in subway maps showing hydrographic elements (Forrest, 2015).

In Stage 3 we sought to determine the user's experience of using indoor maps and the importance of this type of map for the user. Figure 9 shows the questionnaire questions along with the answers given. Table 2 provides considerations regarding the questions and comments made by users (Stage 3 ).

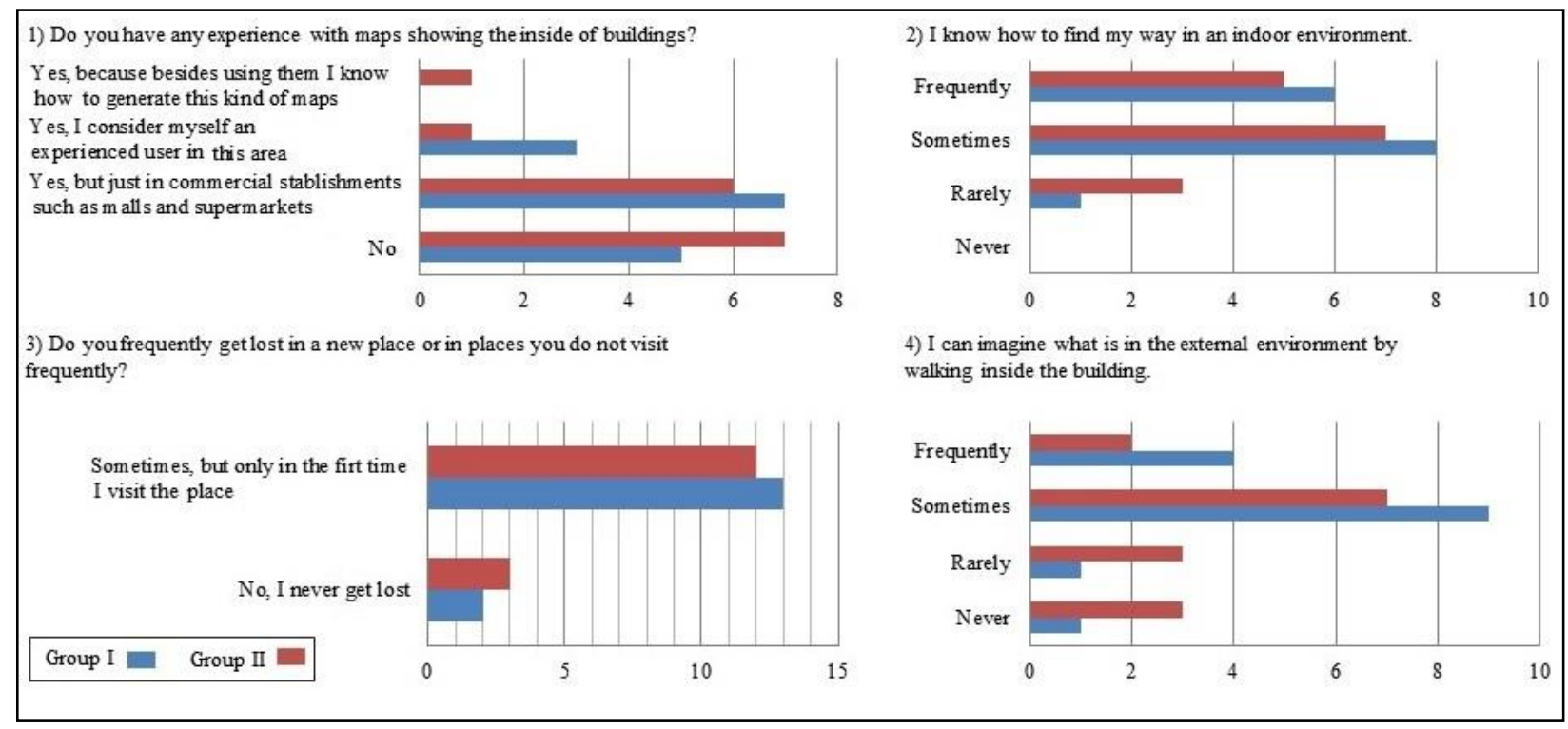

Figure 9: Use of indoor maps (Stage 3). 
Table 2: Use of indoor maps (Stage 3)

\section{Stage 3 Results}

Q1: 12 users were aware of existence of indoor maps but did not use them because they did not know where to find them in the building. They preferred to learn about the environment by walking between spaces.

Q2: Users answering "Rarely" mentioned that they use verbal information from third parties to get orientation and reach their destination. Users answering "Sometimes" mentioned being able to achieve orientation in noncomplex structures with spaces subdivided by categories (food court, leisure, sales). Users answering "Frequently" mentioned looking for information signs and patterns in the structure.

Q3: In relation to the option "Sometimes, but only the first time I visit the place", despite feeling disorientated, users considered it to be normal to get lost in places they are not familiar with. Groups I and II have similar characteristics. For this reason, we believe that none of the map evaluation results have been favored due to ease of user orientation.

Q4: Users answering "Maybe" and "Confident" mentioned looking through the window to find spatial reference points outside the building (streets, shops, squares, among others).

Stage 4 established the relationship between the user and the area being studied. The questions ask about the frequency of visits to the building; the area that the user walks through when in the building; finding their direction in the building (how they orient themselves); memorization of entrances (doors, elevators, stairs); knowledge of the relationship between the indoor and outdoor environment; and the user's level of confidence in providing information related to the building to other people. Figure 10 presents the questionnaire questions along with the answers obtained (Stage 4). 


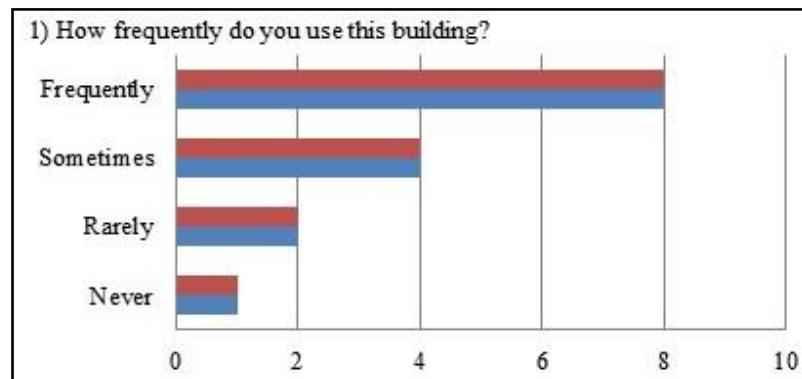

3) In general which area of the building did you go through?

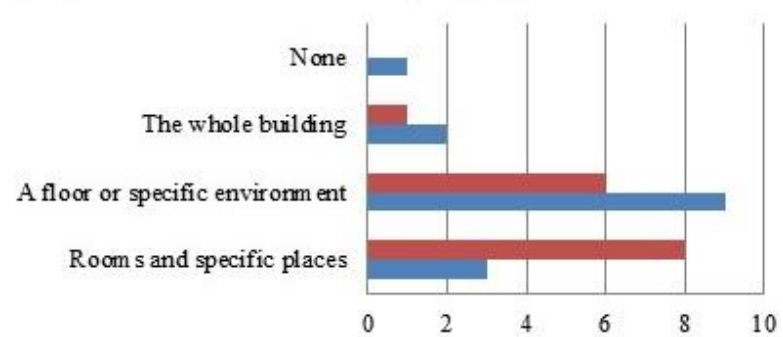

5) Are signs that show different parts of the building and room nomenclature useful to you?

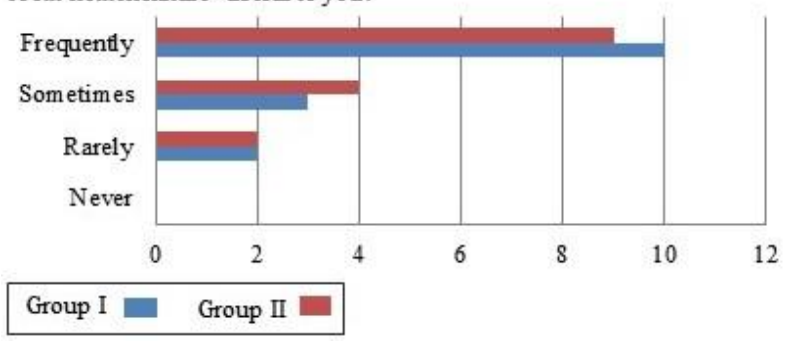

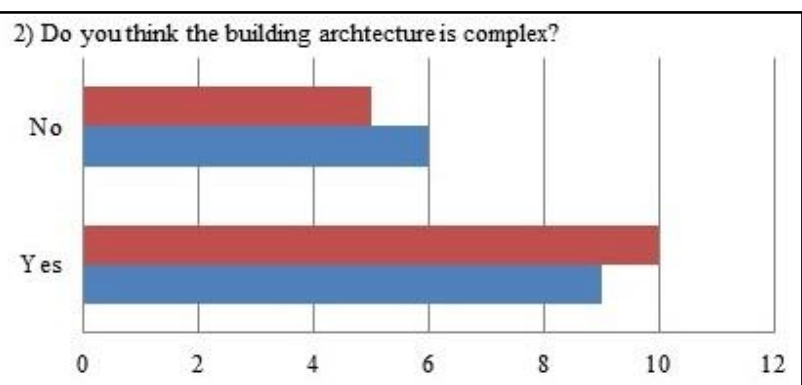

4) Do you feel confident to give information about the building to another person that doesn't know the environment?

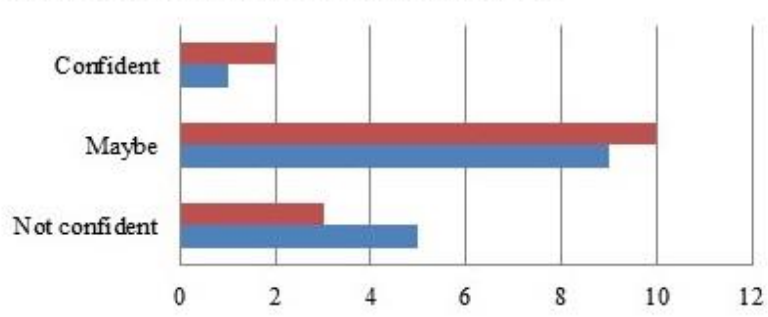

6) Do you observe the building architecture and try to find patterns to get orientation?

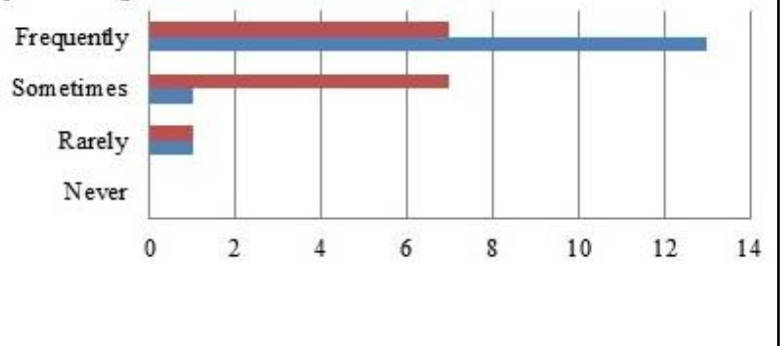

Figure 10: About the area being studied (Stage 4).

Table 3: About the area being studied (Stage 4)

\section{Stage 4 Results}

Q1: Users answering "Never" had gone to the building just to perform the test. Users answering "Rarely" and "Sometimes" did not usually walk in the area being studied. Users answering "Frequently" believed they could orient and navigate themselves in the building because they had prior knowledge of it.

Q2: Users answering "Yes" mentioned that even though they knew the building structure and its rooms, they found it difficult to understand the environment and how it functioned.

Q3: The user who answered "None" mentioned being in the building just to do the test. Users opting for "The whole building" thought they walked throughout the entire building on a daily basis. Users opting for "A specific floor or environment" stated doing tasks at least twice a week in the area. Users answering "specific rooms and places" walked in the area only when looking for specific things there.

Q4: Users answering "Confident" believed that they knew the area being studied. Users selecting "Maybe" had a notion of the location of the building's sectors and blocks.

Q5: Users answering "Frequently" mentioned the importance of updated information signs with easy visual identification as well as adequate symbology in the building. Users answering "Sometimes" mentioned using the signs when performing searching tasks in the environment.

Q6: Users answering "Frequently" and "Sometimes" looked for direction patterns in the corridors and/or looked through the windows at outdoor objects in order to locate themselves. 
Stage 5 focused on user positioning and orientation tasks based on the maps. The questions approached the user's internal route and were related to the use of the symbology adopted in the representation, and the usefulness of orientation signs displayed in the buildings (identification signs found in the environment). The users were asked to perform the task "Point" (identify the represented element in the physical environment and point to its location; and to find specific rooms and points based on maps (walk to the required place). Groups I and II were divided according to their prior knowledge about the building structure, i.e. users familiar or not familiar with walking in the buildings, "Experienced user" and "User with no experience". Figures 11 and 12 present the questionnaire questions along with the answers obtained. Tables 4 and 5 provide considerations regarding the questions and comments made by the users (Stage 5 ).

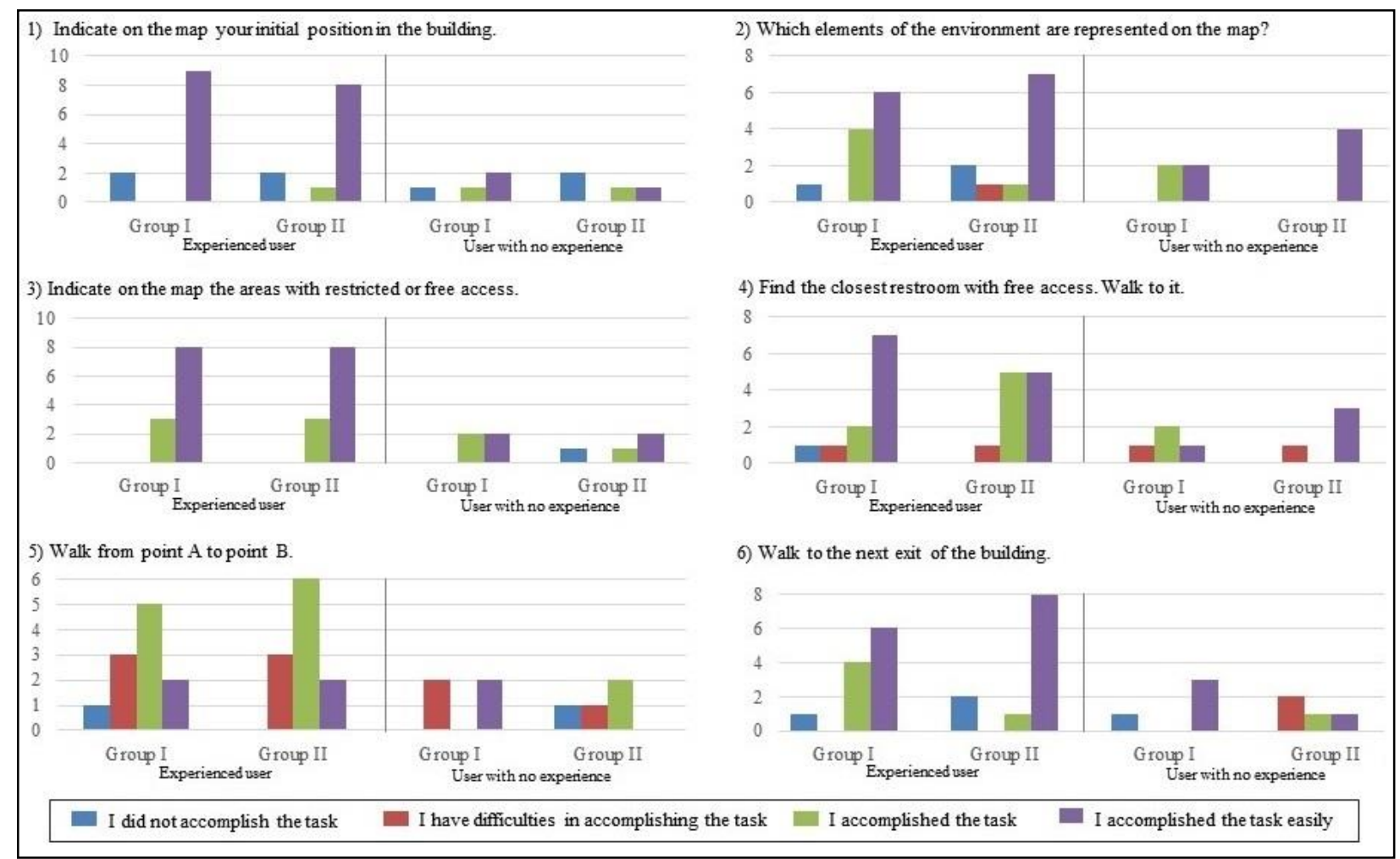

Figure 11: Spatial orientation tasks with indoor maps (Stage 5).

Table 4: Spatial orientation tasks with indoor maps (Stage 5)

\section{Stage 5 Results}

Q1: At the beginning of the test users had to indicate their initial position in the building, in order to move to the area represented on the map. Factors associated with lack of attention as well as mental confusion related to the structural complexity of the building were mentioned by users who stated having difficulties in accomplishing the task.

In Group I, an "Experient User" and a "User with no experience" rotated the position of the cartographic base through $180^{\circ}$ (opposite to pointing north). As a result, they pointed incorrectly to their current position. The users stated that the mistake happened owing to lack of attention, as they confused the outline of the building's blocks. 
Table 4: Cont.

Q2: Users had to find the area represented by the map and go to the place indicated. After finding the place, they had to point to elements they had seen in the environment and that were present on the map.

Users answering "I did not accomplish the task" did not use the feature attribute visualization resource on the map. They walked to the place they thought was indicated on the map based on counting the blocks of the building. All users frequently looked through the window in search of elements that could help with the task.

Q3: Users received the information that some corridors might have access restrictions, but that their use was not prohibited. As such, they had to point on the map to corridors possibly having "Free" or "Restricted" access.

Group II users who answered "I did not accomplish the task" said that they did not realize that the differentiated colors categorized "Restricted" (red) and "Free" (green) routes.

Q4: Starting from the same point, users had to walk to the closest restroom (female/ male/ special use) with free access and were allowed to walk on and between both floors of the building.

When answering "I did not accomplish the task", a Group I user stated having problems in understanding the restrictions shown by the symbology and felt frustrated about the time wasted in order to understand it. After failing to find the restroom the user quit the task. When answering "I have difficulties in accomplishing the task", users mentioned time wasted in order to understanding the symbology. They accomplished the task at the second attempt, after using the change floors and select attributes tools. Users answering "I accomplished the task" considered themselves to be disoriented when using the 'change floors' tool.

Q5: The users started from position A (stationery shop) and had to walk to position B (Environmental Engineering Course Office), being provided with information about the floor and name of the place.

When answering "I did not accomplish the task", the Group II "User with no experience" mentioned a feeling of disorientation after changing floors. The Group I "Experienced user" had problems in relating the room symbology on map with the places in the environment and did not accomplish the task.

When answering "I have difficulties in accomplishing the task", the "Experienced user" group did not use the map to get orientation because they thought they knew the area being studied. When they got lost, they used the map. The Group I "Users with no experience" overlapped the two floors of the building and after finding their position in the building, they rotated the map to the direction that they should take to get to point B.

All users who answered "I accomplished the task" had problems in finding their initial position on the map after changing floors. Three of the Group I "Experienced users" did not use the map rotation tool and mentioned that they felt confused when using it.

Q6: From Position B users had to walk to the next exit on the "Free" or "Restricted" map. In order to accomplish the task, users had to change the floor (storey) on the map and identify the symbol used for the nearest "Exit" feature.

Users who answered "I did not accomplish the task" walked to the corridors on the ground floor and pointed the first exit that they saw without using the map. Users answering "I have difficulties in accomplishing the task" had problems in relating the representation symbology to the physical exit, because the exit was blocked at the time of the test. The four users who answered "I accomplished the task" searched for the exit symbol on the second floor. 


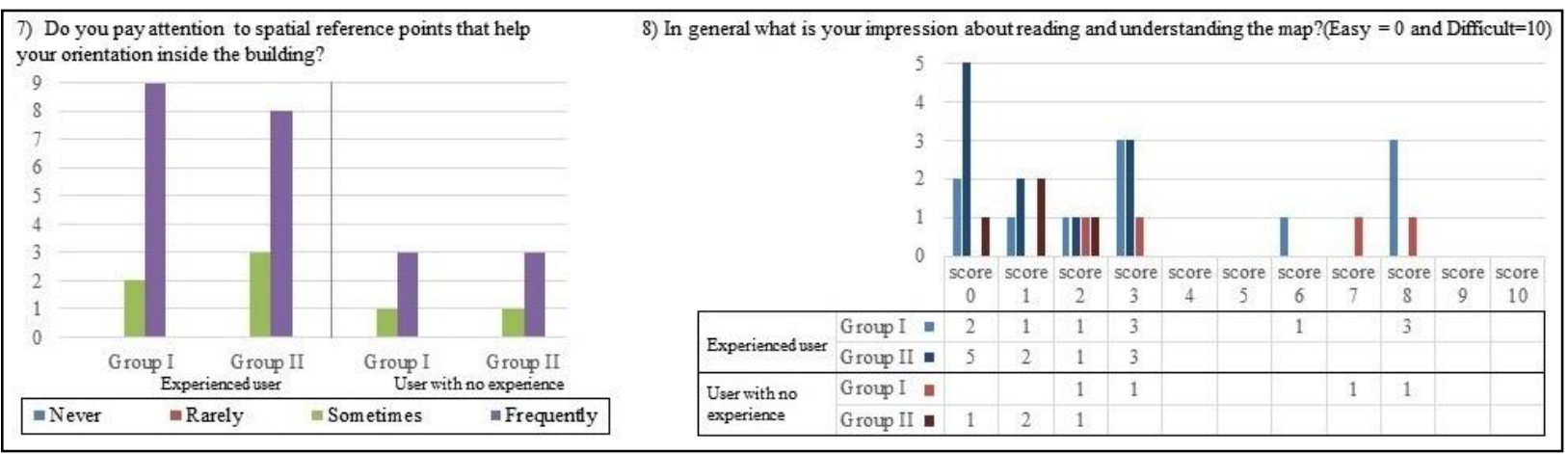

Figure 12: Spatial orientation tasks with indoor maps (Stage 5).

Table 4: Spatial orientation tasks with indoor maps (Stage 5)

\section{Stage 5 Results}

Q7: The question determined the level of importance of the spatial reference points used in the spatial orientation process.

Out of the sample of thirty, twenty-three users said that they frequently used the points that they judged to be easy to visualize, such as restrooms, stairs. And seven users mentioned just using the reference points to determine their current position on the map, such as when changing floors.

Q8: As part of the map assessment, users had to describe their degree of difficulty in reading and understanding the map by giving scores from 0 to 10 (Easy=0 and Difficult=10). The "Experienced users" scores varied greatly. Three people who used the Floor Plan classified its difficultly with a score of 8, while the three people who used the Schematic Map classified its difficulty with a score of 3.

The variation between scores can be seen in the "User with no experience" column. The minimum Group I score was 2 and the maximum was 8 , different to Group II which did not have large variations in the degree of difficulty, having a maximum score of 2 and a minimum of 0 .

Table 5 presents the elements of the physical environment used as a reference for positional orientation by users which they mentioned while performing the tasks requested.

Table 5: User's choice by option

\begin{tabular}{l|c|c|c|c|c|c|c}
\hline \multicolumn{1}{c|}{ Options } & Total & Options & Total & Options & Total & Options & Total \\
\hline Stairs & 24 & Services stores & 13 & Bathroom & 17 & Way out & 2 \\
\hline Lift & 1 & Laboratories & 8 & Classroom & 16 & & \\
\hline
\end{tabular}


Table 6 presents the additional information found on the maps or in the environment that helped the users in the process of spatial orientation while performing the tasks.

Table 6: References used in tasks

\begin{tabular}{l|c|l|c}
\hline \multicolumn{1}{c|}{ Options } & Total & \multicolumn{1}{c|}{ Options } & Total \\
\hline Name & 24 & Floor & 28 \\
\hline Type & 23 & Access (free/restricted) & 18 \\
\hline \multicolumn{1}{c|}{ Others } & & & Others \\
\hline Class Room & 2 & Café/restaurant & 1 \\
\hline Stairs & 4 & Google base map & 1 \\
\hline Corridors & 1 & Fire equipment & 1 \\
\hline Signs (information/directions) & 5 & Building visual identification & 1 \\
\hline Bathroom & 2 & & \\
\hline
\end{tabular}

Some Group I "Experienced users" stated that the Floor Plan requires the user to spend time thinking when reading the map, this being a fact that could make it difficult for inexperienced users to use the map. On the contrary, Group II considered the symbology easy to visualize and understand. These users said that the way the corridors were represented using lines made it easy to move inside the indoor environment. Even users that had difficulties in accomplishing the tasks considered that the map itself was not related to the problems mentioned and described other factors, such as lack of attention, difficulty in using devices and failure to use all the tools available on the map, as being responsible for the problem. Although we cannot state that there is a correlation between the familiarity with mobile devices and the accomplishment of the tasks, users who were familiar with mobile devices performed the test in 20 to 40 minutes, while users unfamiliar with the technology, performed the tests in $1 \mathrm{~h}$ to $1 \mathrm{~h} 30$.

The classification of Types of Use of Indoor Space by color tone gave rise to problems in distinguishing features on the Floor Plan. As the rooms were represented through the primitive graphic area, the number of classes used to distinguish between environments needed to be increased. This factor confused users and increased the time spent on reading the map. Four Group I users, despite considering the map easy to understand, mentioned difficulty in selecting room features because of the proximity of elements. They commented that including specific symbology in certain places could facilitate the reading of the map. As the Schematic Map indicates the positions of the rooms using a single symbol (restaurant: cutlery symbol, stationery shop: pin symbol) users associated the symbology with the places instinctively, without needing to consult the attributes of the feature.

In relation to the symbology used to indicate corridors having restrictions, 11 Group I users and 6 Group II users, despite having been informed that "Restricted" access related to areas of the building that at given times could be blocked, mentioned that they avoided walking in "Restricted" corridors because of the red color on the representation causing a mental block that stopped them from walking there.

Out of the total sample, 9 Group I users and 3 Group II users needed to ask to the interviewer how the types of rooms were classified and their respective colors on the representation. The "Other" category confused the 
users because it covered various types of room use (administration offices, storerooms). Seven users mentioned that the elements comprising this category should be represented by specific symbology related to the type of room use.

Despite the preference for the Schematic map, users mentioned some elements (text information and symbology) that can expand its use and make orientation in the environment easier. The inclusion of tools that provide the estimated location of the user inside the environment such as "You-Are-Here" maps; calculation of routes between points; adding visual elements to distinguish the blocks and storeys of the building; including specific symbology for fire fighting equipment; adding information about accessibility for the physically disabled were the elements mentioned in this study.

\section{Conclusion}

The provision of information about the inside of buildings through maps helps the user who is navigating in the area and seeking to understand and assimilate elements present in the structure as a means of finding their starting position and defining the location of a specific place in the environment. Adding this information increases the process of user spatial orientation. Hence the importance in the evaluation of the representations showing restrictions in this environment. The evaluation of Floor Plans and Schematic Maps by means of questionnaires and tasks related to spatial orientation in indoor environments indicates elements found in the environment and in the indoor representation that directly influence the process of user spatial orientation.

It is noteworthy that the format of the building structure, the number of storeys, the lack of signs, the shape of corridors and visual access to the physical elements found in the building were indicated as being problems arising from the physical environment. The users did not directly associate these problems with the representation.

As mentioned in Forrest's research (2015) on the question of using hydrographic features in IndoorTubeMaps, in the case of indoor maps, using the background base provided a visual restriction between the indoor and outdoor environment that facilitated user spatial orientation. Some of our study participants mentioned that combining the Google cartographic base and indoor maps helped their interpretation and understanding of the represented information. This fact should be taken into consideration in future research.

The problem described by Montello (2010), regarding lack of user orientation caused by misaligned maps, can be minimized with the aid of rotation, pan e zoom tools included in digital maps. However, this option creates issues related to users not having the habit of using the device needed for visualizing digital maps (tablet). In our research, users who were not used to mobile devices mentioned feeling uncomfortable about using the device, in addition to feeling irritated, and this hinders the mental determination of their current position in the environment. This factor could increases the time spent on achieving spatial orientation, thus this factor needs more investigation.

However, further studies are needed to establish the relevance for users of the representation of such information. Our research also provides possible elements that can be used as reference points inside the area being studied, such as stairs, bathrooms, shops and classrooms, these being the elements most mentioned by the users. However, as the group of users was comprised of only 30 persons and just one type of indoor 
environment was tested, it is not possible to affirm that these elements could help the user orientation in other cases. Therefore, additional studies are needed in the area of indoor mapping related to user orientation and adequate ways of representing such environments.

\section{Acknowledgement}

The authors would like to thank the Conselho Nacional de Desenvolvimento Científico e Tecnológico (CNPq) and Coordenação de Aperfeiçoamento de Pessoal de Nível Superior (CAPES) for their financial support (Process: 459300/2014-8 - Edital Universal; Process: 310312/2017-5 - Produtividade em Pesquisa).

\section{References}

Anand, S. Avelar, S. Ware, J. M. Jackson, M. 2000. Automated schematic map production using simulated annealing and gradient descent approaches.

Antunes, A. P. 2016. Avaliação de pontos de referência com uso de QR-CODE para posicionamento em ambiente indoor. Diss. Federal University of Paraná.

Antunes, A. P. Castro, M. C. Sarot, R. V. Delazari, L. S. 2017. Determinação de elementos relacionados à avaliação da usabilidade de interfaces de mapas colaborativos. In: UNESP, IV Simpósio Brasileiro de Geomática. São Paulo, Brazil, 24-26 July 2017, pp.077-083.

Avelar, S. Hurni, L. 2006. On the Design of Schematic Transport Maps. Cartographica the International Journal for Geographic Information and Geovisualization, v.41, pp.217-228.

Darken, R. P. Peterson, B. 2002. Spatial Orientation, Wayfinding, and Representation. In: K. Stanney (Ed.), Handbook of Virtual Environment Technology. Mahway, NJ: Erlbaum, pp.493-518.

Delazari, L. S. Anand, S. Santos, R. Morley, J. 2014. Evaluation of subjective preferences regarding indoor maps: comparison of schematic maps and floor plans. International Conference on Geographic Information Science. In: Huerta, Schade, Granell (Eds): Connecting a Digital Europe through Location and Place, Proceedings of the AGILE'2014, Castellón, Spain, 3-6 June 2014.

Dogu, U. Erkip, F. 2000. Spatial Factors Affecting Wayfinding and Orientation: A Case Study In a Shopping Mall. Environment and Behavior, 32(6), pp.731-755.

Haeberling, C. 1999. Symbolization in topographic 3D-maps: conceptual aspects for user-oriented design. In: ICA/ACI, 21th International Congress of Cartography. Ottawa v.2, pp.1037-1044.

Huang, H. Gartner, G. 2010. A Survey of Mobile Indoor Navigation Systems. In: Cartography Central Eastern Europe, Berlin, Germany: Springer, pp.305-319.

Forrest, D. 2015. Causes and consequences of scale change in schematics maps: are users aware and do they care?. In: ICC, 27th International Cartographic Conference/16th General Assembly. Papers: Art, Culture and Cartography, Rio de Janeiro, Brazil, 23-28 June 2015, n.310. 
Guo, Z. 2011. Mind the Map! The Impact of Transit Maps on Travel Decisions in Public Transit. In: Transportation Research Part A: Policy and Practice, 45 (7), pp.625-639.

Lehtinen, V. Nurminen, A. Oulasvirta, A. 2012. Integrating spatial sensing to an interactive mobile 3D map. In: 3D User Interfaces, IEEE Symposium on 3D User Interfaces, March 2012, pp.11-14.

Montello, D. R. 2010. You are where? The Function and Frustration of You-Are- Here (YAH) Maps. Spatial Cognition \& Computation: An Interdisciplinary Journal, 10(2), pp.94-104.

Nossum, A. S. 2011. IndoorTubes a Novel Design for Indoor Maps. Cartography and Geographic Information Science, 38, pp. 193-201.

Nossum, A. S. 2013. Developing a Framework for Describing and Comparing Indoor Maps. The Cartographic Journal, 50, pp.218-224.

OGC. 2014. IndoorGML. In: Open Geospatial Consortium Inc, Reference Number OGC 14-005, v.0.8.2, January 2014.

Presson, C. Hazelrigg, M. 1984. Building spatial representations through primary and secondary learning. Journal of Experimental Psychology: Learning, Memory, and Cognition, 10, pp.716-722.

Sarot, R. V. 2015. Avaliação de mapas indoor para dispositivos móveis para auxílio à tarefa de orientação. Diss. Federal University of Paraná.

Schiller, J. Voisard, A. 2004. Location-Based Services. Morgan Kaufmann.

Schmidt, M. A. R. 2012. Uso de Mapas 3D para Navegação Virtual: Uma Abordagem Cognitiva. PhD. Federal University of Paraná.

Vinson, N. G. 1999. Design Guidelines for Landmarks to Support Navigation in Virtual Environments. In: Proceedings of the SIGCHI Conference on Human Factors in Computing Systems. Pittsburgh, USA. pp.278-285.

Zlatanova, S. Sithole, G. Nakagawa, M. ZHU, Q. 2013. Problems in Indoor Mapping and Modelling. In: ISPRS Acquisition and Modelling of Indoor and Enclosed Environments, Remote Sensing and Spatial Information Sciences, Cape Town, South Africa, pp.63-68. 